\title{
Primary malignant melanoma of the female urethra: a rare case of cytological observation
}

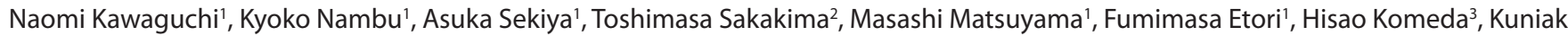 \\ Hirai ${ }^{1}$, Naoki Watanabe' ${ }^{1}$, Takafumi Naiki ${ }^{2}$, Tetsuya Yamada ${ }^{4}$ and Takuji Tanaka ${ }^{1,5^{*}}$ \\ *Correspondence: takutt@gmhosp.gifu.gifu.jp

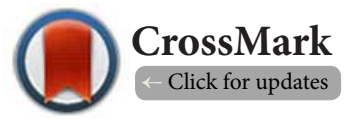 \\ 'Department of Diagnostic Pathology (DDP) and Research Center of Diagnostic Pathology (RC-DiP), Gifu Municipal Hospital, 7-1 \\ Kashima-cho, Gifu City, Japan. \\ ${ }^{2}$ Department of Central Laboratory, Gifu Municipal Hospital, 7-1 Kashima-cho, Gifu City, Japan. \\ ${ }^{3}$ Department of Urology, Gifu Municipal Hospital, 7-1 Kashima-cho, Gifu City, Japan. \\ ${ }^{4}$ Department of Diagnostic Pathology, Kizawa Memorial Hospital, 590 Shimofurui, Furui-machi, Minokamo City, Japan. \\ ${ }^{5}$ Department of Tumor Pathology, Gifu University Graduate School of Medicine, 1-1 Yanagido, Gifu City, Japan.
}

\begin{abstract}
We herein report a rare case of primary malignant urethral melanoma developed in an elderly Japanese patient with hypertension, diabetes and hyperlipidemia. An 80-year-old female presented at our hospital with a history of urodynia and perineal pain lasting for several months. Cystoscopy revealed cystitis and urethritis with erosion. At that time, urinary cytology was negative for malignancy, although melanophages were observed. Four months later, lower abdominal computed tomography and magnetic resonance imaging indicated urethral tumors. Urinary cytology subsequently detected malignant melanoma, and a biopsy of the urethra confirmed malignancy. Although inguinal lymph node metastasis was found 16 months postoperatively, the patient has remained free of disease for more than six years after surgery and chemotherapy.
\end{abstract}

Keywords: Malignant melanoma, urethra, female, urinary cytology, immunohistochemistry

\section{Introduction}

Primary melanoma of the genitourinary tract is rare, accounting for less than $1 \%$ of all cases of melanoma [1,2], while primary malignant melanoma of the urethra in females represents only $0.2 \%$ of all malignant melanomas [3]. Since the clinical presentation of urethral melanoma is similar to that of urothelial carcinoma, there is frequently a delay in diagnosis [4]. According to the literature, most cases of malignant melanoma in the female urethra involve the meatus and/or distal urethra [5]. Common clinical signs include bleeding, discharge, voiding dysfunction and the presence of tumorous masses [6]. Clinical misdiagnosis and delayed diagnosis of urethral melanomas result in a poor prognosis [6]. In this report, we present a case of malignant melanoma originating from the urethra in an elderly Japanese female and discuss the cytological and immunohistochemical findings.

\section{Case report}

On November 16, 2009, an 80-year-old female presented to our hospital with urodynia and perineal pain lasting for several months. She had no history of urogenital symptoms or diseases, although she had hypertension, hyperlipidemia and diabetes. At presentation, the results of a chest $\mathrm{X}$-ray and routine serum biochemistry tests were normal, with the exception of the levels of lactate dehydrogenase $(230 \mathrm{IU} / \mathrm{L})$, blood urine nitrogen $(25.7 \mathrm{mg} / \mathrm{dl})$ and creatinine $(0.84 \mathrm{mg} / \mathrm{dl})$. A urinalysis showed cloudiness of the urine with macrophages containing brown granular pigments [7] (Figure 1a). Urinary cytology (conventional smears) was negative; however, a few macrophages containing brown granules were noted (Figure 1b). A cystoscopic examination showed necrotic and edematous mucosa in the trigone of the urinary bladder, bladder neck and urethra. The patient was diagnosed with non-specific cystitis and given antibiotics. Her symptoms disappeared; however, the findings of cystoscopy did not improve. Lower abdominal computed tomography (CT) showed slight thickening of the lower wall of the urinary bladder (Figure 2), while magnetic resonance imaging (MRI) detected flat elevation ( $4 \mathrm{~cm}$ in width) at the internal ostium of the urethra (Figure 3). Three months later, urinary cytology disclosed the presence of atypical 


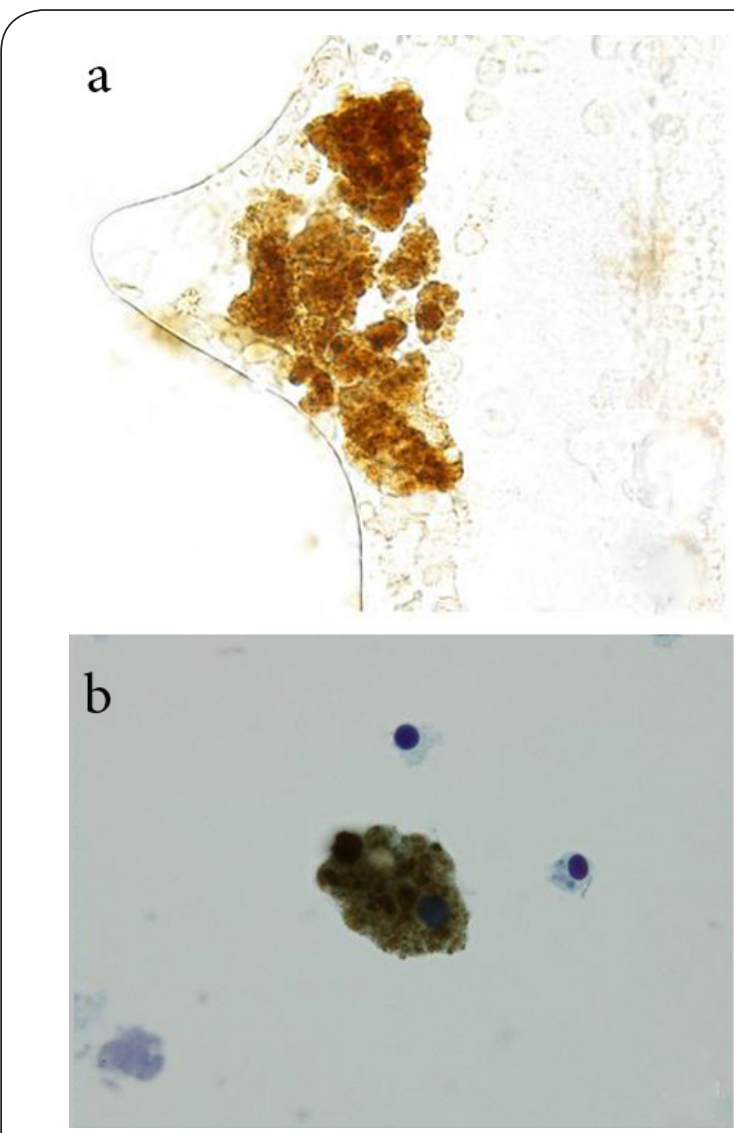

Figure 1. Urinalysis and urinary cytology (conventional smear). (a) Macrophages containing brown granular pigments (melanophages) in the urinary sediment upon presentation of the patient in our hospital. (b) Melanophages in the urinary cytology assessed upon presentation of the patient to our hospital. Original magnification, (a) and (b): $\times 400$.

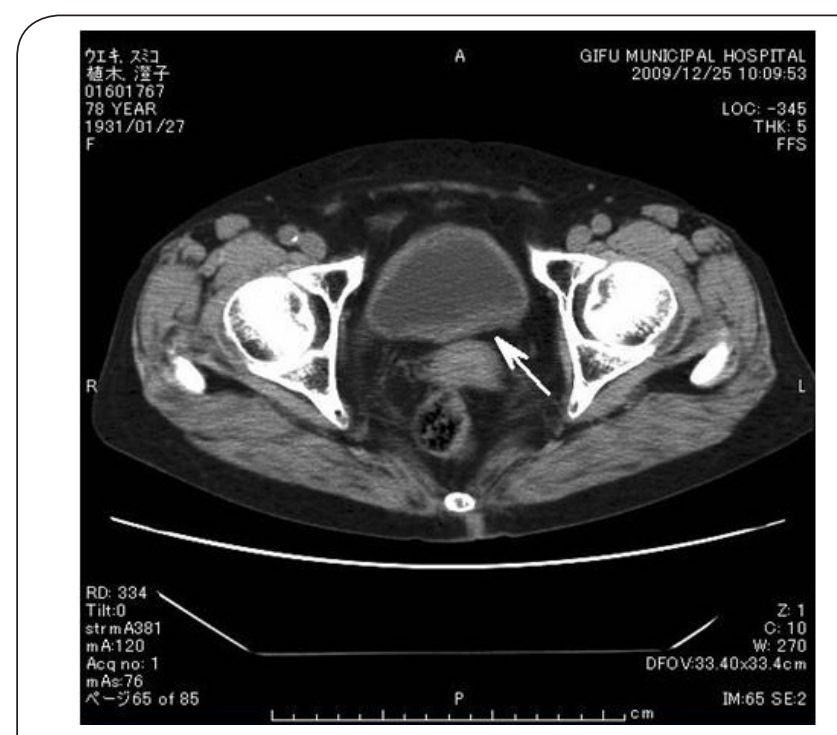

Figure 2. CT shows slight thickening (arrow) of the lower wall of the urinary bladder. cells containing brown pigments suggestive of malignant melanoma (Figure 4), and a pathological examination of biopsy specimens of the bladder (obtained via transurethral resection) and urethra revealed malignant melanoma of the urethra (Figures $\mathbf{5 a}$ and $\mathbf{5 b}$ ). Melanin pigments were detected according to the Fontana-Masson technique (Figure 5c). In addition, the superficial lymph nodes were palpable; however, no findings suggestive of metastasis were found on an abdominal examination.

The patient underwent extensive surgery, including cystourethrectomy, vaginectomy, vulvectomy and regional lymph node dissection. A gross examination of the resected specimen revealed black lesions in the urethra and bladder neck (Figure 6), and a microscopic examination demonstrated infiltration of pigmented tumors cells around the urethral epithelium (Figure 7a). The tumor cells were large epithelioids with dusty black melanin pigments and frequent mitotic figures (Figure 7b). Immunohistochemistry showed the malignant cells to be immunoreactive for HMB-45 (Figure 7c) and S-100 protein (Figure 7d). A macroscopically clean surgical margin was obtained, and subsequent histology revealed a microscopic negative margin. In addition, there was no evidence of any other primary tumors, including skin melanoma. Based on these findings, we diagnosed the patient with primary malignant melanoma of the urethra. Although she received chemotherapy [DAV therapy: DTIC (dacarbazine), ACNU (nimustine) and VCR (vincristine)], 16 months after the surgery, metastasis was detected in the right inguinal lymph nodes, which were consequently removed. The patient is currently under close follow-up every four months. She has experienced no episodes of recurrence of melanoma, including systemic metastasis, for more than six years, as assessed on chest, abdominal and pelvic computed tomography.

\section{Discussion}

Malignant melanoma originates from melanoblasts differentiated from neuroectoderm neural crest cells. Neural crest cells differentiate to melanocytes in the skin, oral mucosa, nasal mucosa and vulva; therefore, malignant melanoma occurs in these regions. Most malignant melanomas develop in the skin, accounting for $81 \%$ of all cases of melanoma. In contrast, the rate of malignant mucosal melanomas is $17 \%$, and these lesions mostly develop in the eyelid and eyeball. We previously reported a case of primary malignant melanoma in the urinary bladder [8]. In addition, a case of simple melanosis of the urinary bladder was recently reported [9]; this rare condition is occasionally associated with malignant melanoma.

Malignant urethral melanomas, which usually originate from the distal urethra [3], account for $0.2 \%$ of all malignant melanomas and $4 \%$ of all urethral cancers [5]. The first case of malignant urethral melanoma was reported by Tyrell and Reed more than 100 years ago $[6,10]$. Malignant urethral melanoma is three times as common in females as in males and is more frequent in the Caucasian population. Most cases are 


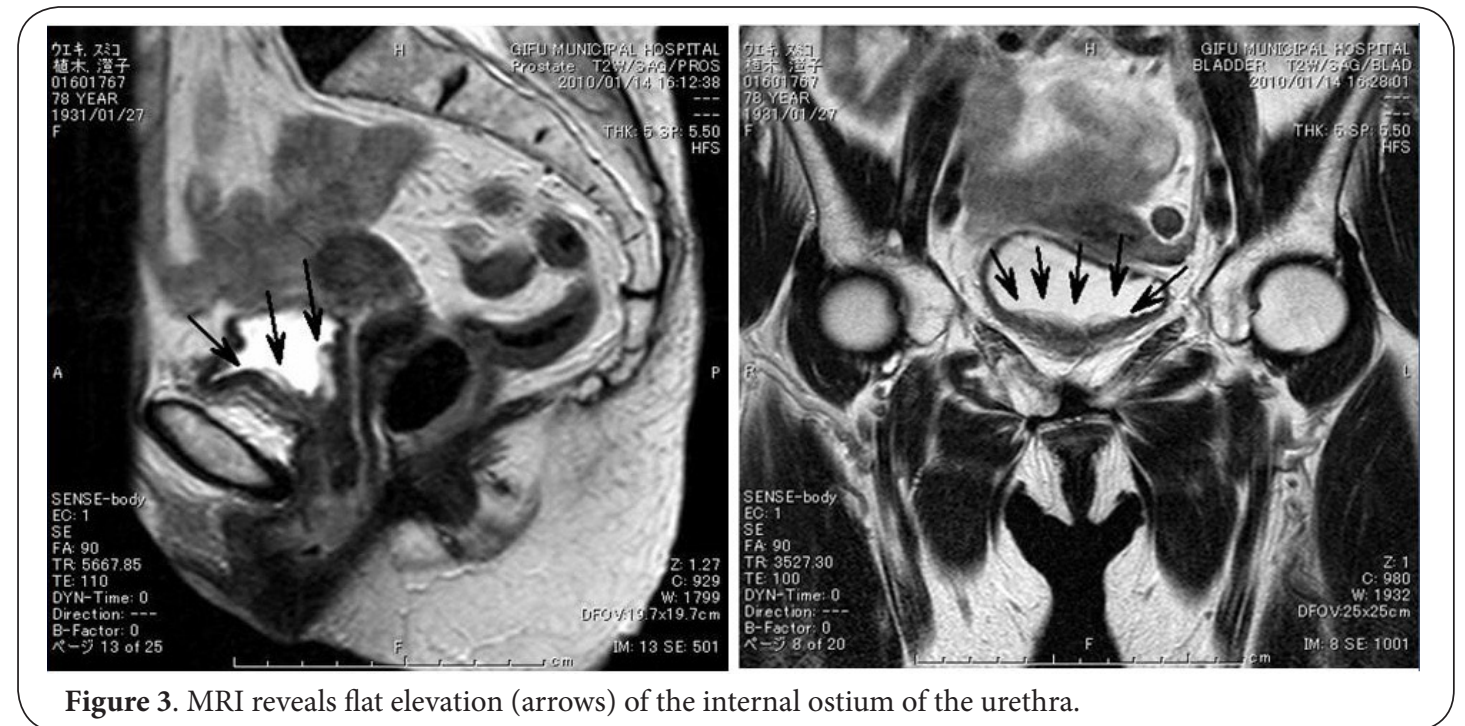

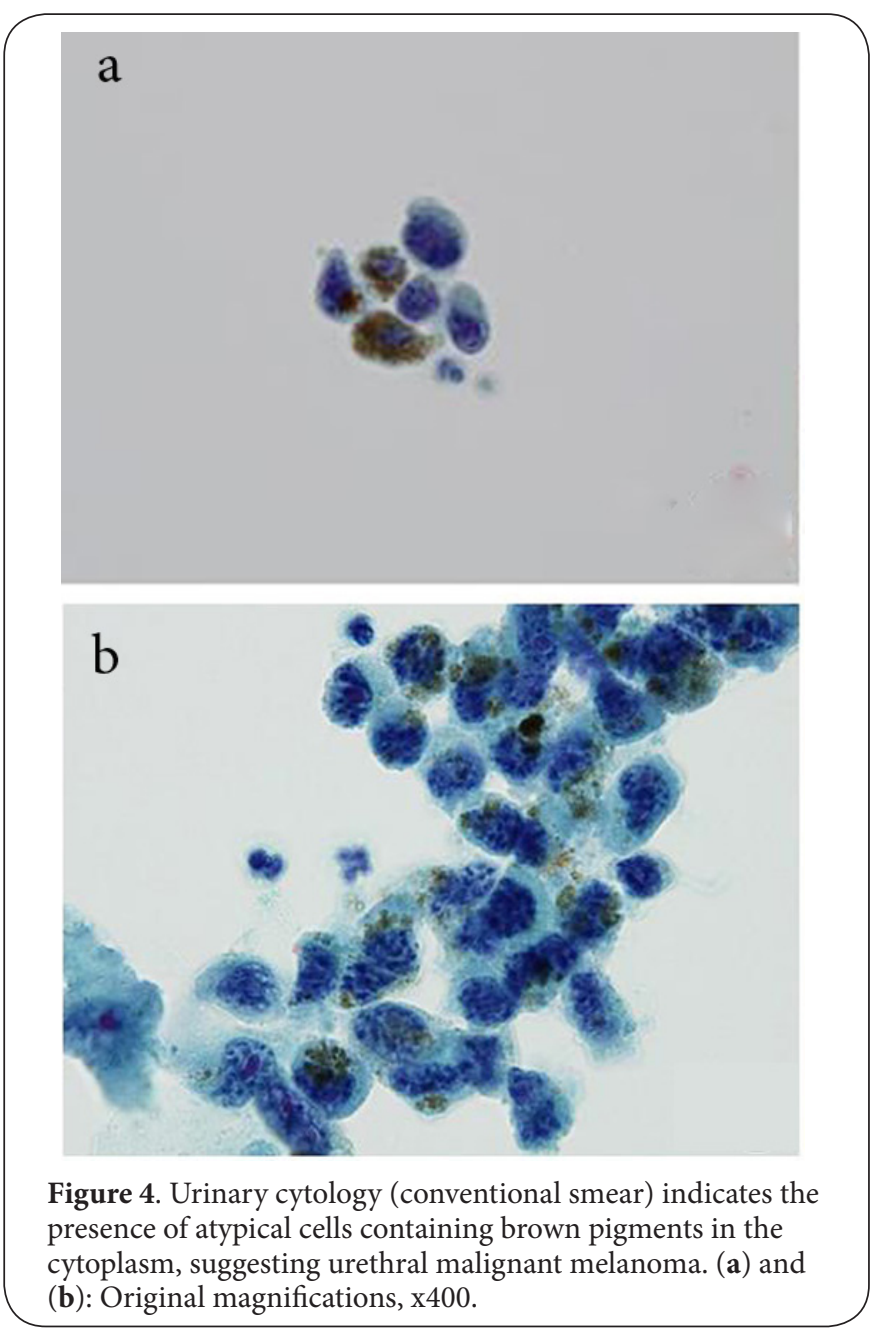

diagnosed after 50 years of age $[1,11]$, with an average age of 64 years [12]. Presenting symptoms include vaginal bleeding,

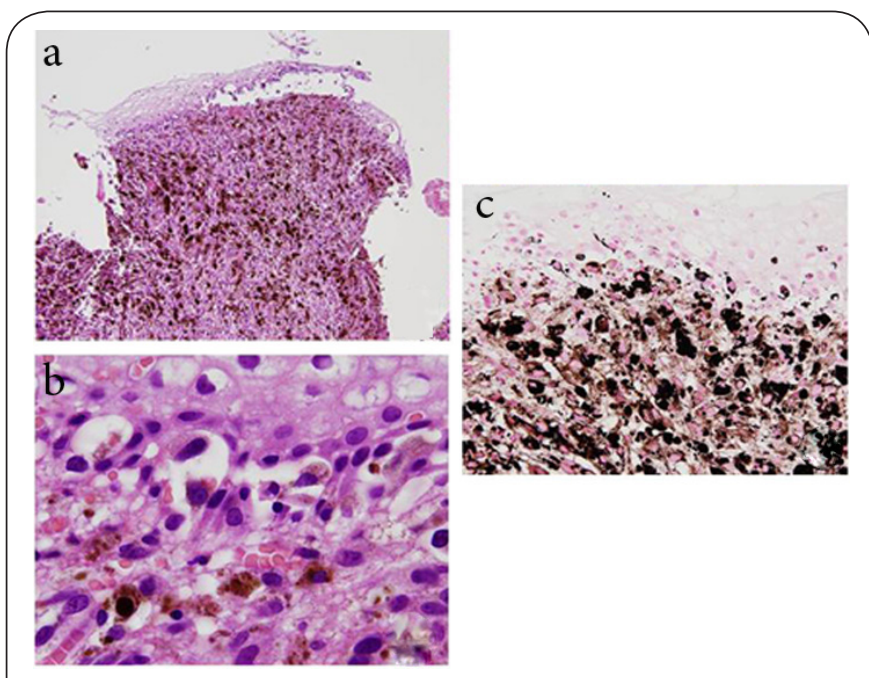

Figure 5. Histopathology of the urethral tumor. (a) Pigmented tumors cells proliferating and infiltrating under the urethral epithelium. (b and c) Melanoma cells in the subepithelial region with black granules in the cytoplasm of the tumor cells. (a) and (b): H \& E stain. (c) Fontana-Masson stain. Original magnifications (a) $\times 40$, (b) $\times 400$ and (c) $\times 80$.

masses, hematuria and dysuria with a decreased urinary stream [13]. Although urethral melanomas are typically polypoid [11], our case was not. Since one-fifth of primary malignant urethral melanomas are amelanotic [11], physicians should carefully differentiate primary neoplasms involving the urethra.

In the present case, we suspected urogenital malignant melanoma upon presentation of the patient to our hospital, based on the presence of melanophages in the urinalysis and urinary cytology. Three months later urethral malignant melanoma was confirmed by urinary cytology and other examinations, suggesting that the cytological method helped us to make our final diagnosis. 


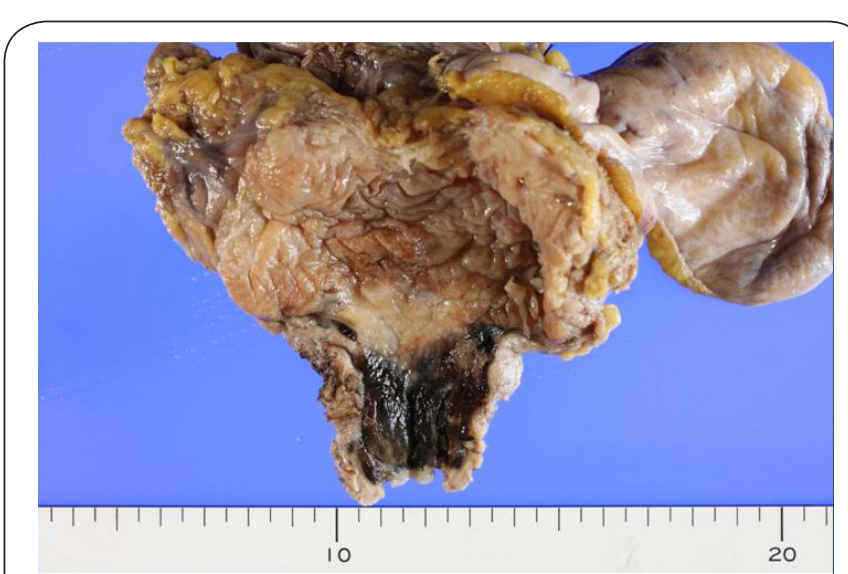

Figure 6. Macroscopic view of the resected urinary bladder and urethra. Note the black urethral mucosa.

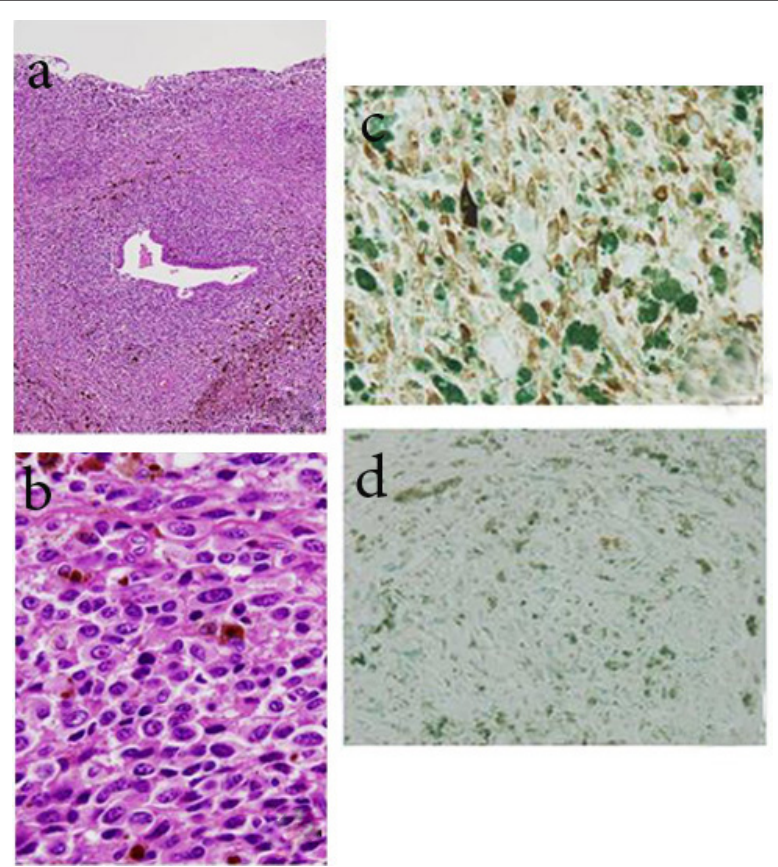

Figure 7. Histopathology of malignant melanoma of the urethra. (a) Melanoma cells proliferating around the urethra. (b) Large melanoma cells containing melanin are seen. The tumor cells were strongly immunoreactive for (c) HMB-45 and weakly immunoreactive for (d) S-100 protein. (a) and (b) H \& E stain. (c) HMG-45 immunohistochemistry. (d) S-100 immunohistochemistry. Original magnifications (a) x40, (b) x400, (c) x400 and (d) x200.

Microscopic examinations of malignant urethral melanomas demonstrates, a wide histologic spectrum of patterns, including diffuse, nested, fascicular, and storiform growth of pleomorphic cells [6]. Immunohistochemistry of melanocyte differentiation is therefore required to obtain an accurate diagnosis of this malignancy. The most frequently used melanocytic markers are S-100 protein and HMB-45. Monoclonal antibodies against S-100 protein react with more than $90 \%$ of melanomas [14].
However, although HMB-45 is quite specific for melanocytic neoplasms, it is less sensitive than S-100 protein for diagnosing melanoma [14]. In the present case, strong immunoreactivity against HMB-45 was conclusively positive in the melanoma cells, whereas the positive reaction to $\mathrm{S}-100$ protein was weak. These findings are similar to those observed in our previous case of malignant urinary bladder melanoma [8], thus suggesting the utility of measuring the HMB- 45 antibody titer for immunohistochemically detecting malignant urogenital melanomas.

Malignant urethral melanomas have a worse prognosis than malignant cutaneous melanomas, as lymph node metastasis is usually found at the time of the initial diagnosis and there is a significant delay in diagnosis in such cases [10]. Malignant urethral melanomas frequently presents as polypoid tumors and are mistaken for other malignant diseases and even benign lesions, including urethral polyps, caruncles, mucosal prolapse or chancres $[6,15]$. Macroscopically, the present case did not involve a polypoid tumor, but rather an elevated lesion that was black in color. Primary malignant urethral melanomas in females tend to metastasize to adjacent areas at an early stage, including the regional lymph nodes and occasionally distant sites via the hematogenous route [16]. In this case, we found inguinal lymph node metastasis 16 months after surgery. However, no further recurrence was noted following resection of the metastatic lymph nodes, although recurrence of urethral melanoma has been reported to occur within 12.5 months [12].

Although the optimum treatment for urethral melanomas in females has not yet been defined, our chemotherapy regimen (DAV therapy) for malignant cutaneous melanoma [17] was effective in this case. Radical surgical resection with postoperative adjuvant chemotherapy or immunotherapy is also recommended. However, there is little clinical experience to support the use of such adjuvant treatment.

In conclusion, we herein reported a case of malignant urethral melanoma in an 80-year-old Japanese female with cytological and immunohistochemical findings that were helpful for making an early and accurate diagnosis of malignant melanoma in the urogenital region.

\section{Competing interests}

The authors declare that they have no competing interests.

\section{Authors' contributions}

\begin{tabular}{|l|c|c|c|c|c|c|c|c|c|c|c|c|}
\hline Authors' contributions & NK & KN & AS & TS & MM & FE & HK & KH & NW & TN & TY & TT \\
\hline $\begin{array}{l}\text { Research concept and } \\
\text { design }\end{array}$ & $\checkmark$ & -- & -- & -- & $\checkmark$ & $\checkmark$ & -- & -- & $\checkmark$ & $\checkmark$ & $\checkmark$ & $\checkmark$ \\
\hline $\begin{array}{l}\text { Collection and/or } \\
\text { assembly of data }\end{array}$ & $\checkmark$ & $\checkmark$ & $\checkmark$ & $\checkmark$ & $\checkmark$ & $\checkmark$ & $\checkmark$ & $\checkmark$ & $\checkmark$ & $\checkmark$ & $\checkmark$ & - \\
\hline $\begin{array}{l}\text { Data analysis and } \\
\text { interpretation }\end{array}$ & $\checkmark$ & -- & -- & -- & $\checkmark$ & $\checkmark$ & -- & $\checkmark$ & $\checkmark$ & $\checkmark$ & $\checkmark$ & $\checkmark$ \\
\hline Writing the article & $\checkmark$ & -- & -- & -- & $\checkmark$ & $\checkmark$ & -- & -- & $\checkmark$ & $\checkmark$ & -- & $\checkmark$ \\
\hline $\begin{array}{l}\text { Critical revision of the } \\
\text { article }\end{array}$ & -- & -- & -- & -- & $\checkmark$ & $\checkmark$ & -- & -- & $\checkmark$ & $\checkmark$ & - & $\checkmark$ \\
\hline Final approval of article & $\checkmark$ & $\checkmark$ & $\checkmark$ & $\checkmark$ & $\checkmark$ & $\checkmark$ & $\checkmark$ & $\checkmark$ & $\checkmark$ & $\checkmark$ & $\checkmark$ & $\checkmark$ \\
\hline Statistical analysis & -- & -- & -- & -- & -- & -- & -- & -- & -- & -- & -- & -- \\
\hline
\end{tabular}


Kawaguchi al. Pathology Discovery 2014,

\section{Acknowledgement}

This work was partly supported by a Grant-in-Aid for the $3^{\text {rd }}$ Terms Comprehensive 10-Year Strategy for Cancer Control from the Ministry of Health, Labour and Welfare of Japan.

Publication history

Editors: Anna Nasierowska-Guttmejer, Clinical Hospital of Ministry of Internal Affiars, Poland.

Jianyu Rao, UCLA Ronald Reagan Medical Center, USA.

Esther Diana Rossi, Catholic University of Sacred Heart, Italy.

Received: 17-Jun-2014 Final Revised: 25-Jul-2014

Accepted: 08-Aug-2014 Published: 20-Aug-2014

\section{References}

1. Gupta R, Bhatti SS, Dinda AK and Singh MK. Primary melanoma of the urethra: a rare neoplasm of the urinary tract. Int Urol Nephrol. 2007; 39:833-6. | Article | PubMed

2. Das P, Kumar N, Ahuja A, Jain A, Ray R, Sarkar C and Gupta SD. Primary malignant melanoma at unusual sites: an institutional experience with review of literature. Melanoma Res. 2010; 20:233-9. I Article I PubMed

3. Akbas A, Akman T, Erdem MR, Antar B, Kilicarslan I and Onol SY. Female urethral malignant melanoma with vesical invasion: a case report. Kaohsiung J Med Sci. 2010; 26:96-8. | Article | PubMed

4. Katz EE, Suzue K, Wille MA, Krausz T, Rapp DE and Sokoloff MH. Primary malignant melanoma of the urethra. Urology. 2005; 65:389. | Article | PubMed

5. Kim CJ, Pak K, Hamaguchi A, Ishida A, Arai Y, Konishi T, Okada Y and Tomoyoshi T. Primary malignant melanoma of the female urethra. Cancer. 1993; 71:448-51. | Article I PubMed

6. Filipkowski LA, Barker MA and Karram MM. Primary genitourinary melanoma presenting as voiding dysfunction. Int Urogynecol J Pelvic Floor Dysfunct. 2009; 20:1141-3. I Article I PubMed

7. Ichiyanagi Y, Sakakima T, Takehara Y, Narita N, Etori F, Yamada T, Komeda $\mathrm{H}$ and Takada $\mathrm{T}$. A case of the urinary-tract malignant melanoma experienced in our institution: The melanoma cells were detected in the urine (in Japanese). Annu. Gifu Municipal Hosp. 2012; 32: 14-16.

8. Kojima T, Tanaka T, Yoshimi N and Mori H. Primary malignant melanoma of the urinary bladder. Arch Pathol Lab Med. 1992; 116:1213-6. | PubMed

9. Talmon GA, Khan AU, Koerber RK and Johansson SL. Simple melanosis of the bladder: a rare entity. Int J Surg Pathol. 2010; 18:547-9. | Article PubMed

10. Sugiyama VE, Chan JK and Kapp DS. Management of melanomas of the female genital tract. Curr Opin Oncol. 2008; 20:565-9. | Article | PubMed

11. Oliva E, Quinn TR, Amin MB, Eble JN, Epstein JI, Srigley JR and Young $\mathrm{RH}$. Primary malignant melanoma of the urethra: a clinicopathologic analysis of 15 cases. Am J Surg Pathol. 2000; 24:785-96. | Article | PubMed

12. El-Safadi S, Estel R, Mayser P and Muenstedt K. Primary malignant melanoma of the urethra: a systematic analysis of the current literature. Arch Gynecol Obstet. 2014; 289:935-43. | Article I PubMed

13. Piedimonte A, Aquinati A, Scalise A and Bertani A. Occult primary melanoma of the urethra: a long-term survival case. Plast Reconstr Surg. 2004; 114:618-9. | Article | PubMed

14. Sheffield MV, Yee H, Dorvault CC, Weilbaecher KN, Eltoum IA, Siegal GP, Fisher DE and Chhieng DC. Comparison of five antibodies as markers in the diagnosis of melanoma in cytologic preparations. Am J Clin Pathol. 2002; 118:930-6. I Article I PubMed

15. Nakamoto $\mathrm{T}$, Inoue $\mathrm{Y}$, Ueki T, Niimi N and Iwasaki Y. Primary amelanotic malignant melanoma of the female urethra. Int J Urol. 2007; 14:153-5. I Article I PubMed

16. Cho ST, Song HC, Cho B, Choi WS, Lee WK, Lee YS, Lee YG, Kim KK, Park $\mathrm{SH}$ and Kim JW. Primary malignant melanoma of the female urethra. Korean J Urol. 2012; 53:206-8. | Article | PubMed Abstract | PubMed Full $\underline{\text { Text }}$
17. Nagatani T, Ichiyama S, Onuma R, Miyazawa M, Matsuzaki T, Miyagawa K, Baba N, Uchiyama M and Nakajima H. The use of DAV (DTIC, ACNU and VCR) and natural interferon-beta combination therapy in malignant melanoma. Acta Derm Venereol. 1995; 75:494. | PubMed

\section{Citation:}

Kawaguchi N, Nambu K, Sekiya A, Sakakima T, Matsuyama M, Etori F, Komeda H, Hirai K, Watanabe N, Naiki T, Yamada T and Tanaka T. Primary malignant melanoma of the female urethra: a rare case of cytological observation. Pathol Discov. 2014; 2:5. http://dx.doi.org/10.7243/2052-7896-2-5 